\title{
INFLUÊNCIA DA ADIÇÃO DE FÉCULA DE MANDIOCA NAS CARACTERÍSTICAS DO PÃO TIPO CHÁ
}

\author{
JUCYANNE CARVALHO VIEIRA* \\ FLÁVIO MARTINS MONTENEGRO** \\ ALESSANDRA SANTOS LOPES ${ }^{* * *}$ \\ ROSINELSON DA SILVAPENA***
}

\begin{abstract}
Estudou-se a adição de fécula de mandioca como substituto parcial da farinha de trigo na produção de pão tipo chá. As matérias-primas (farinha de trigo e fécula de mandioca) e as farinhas mistas (5, 10 e $15 \%$ de substituição de farinha de trigo por fécula de mandioca) foram caracterizadas mediante análises físicas, físico-químicas, análise térmica diferencial (ATD) e microscopia eletrônica de varredura (MEV). A substituição de até $10 \%$ da farinha de trigo pela fécula de mandioca não provocou alteração significativa $(p \leq 0,05)$ na qualidade sensorial e propriedades físicas do pão tipo chá.
\end{abstract}

PALAVRAS-CHAVE: FÉCULA DE MANDIOCA; FARINHA DE TRIGO; PÃO TIPO CHÁ.

* $\quad$ Mestre em Ciência e Tecnologia de Alimentos, Universidade Federal do Pará (UFPA), Belém, PA, Brasil (e-mail: jucyanne_vieira@yahoo.com.br).

** Pesquisador Científico, Cereal Chocotec, Instituto de Tecnologia de Alimentos (ITAL), Campinas, SP, Brasil (e-mail: flavio@ital.sp.gov.br).

*** Professores, Faculdade de Engenharia de Alimentos, Instituto de Tecnologia, UFPA, Belém, PA, Brasil (e-mail: aslopes@ufpa.br e rspena@fpa.br). 


\section{INTRODUÇÃO}

A fécula de mandioca, também conhecida em algumas regiões brasileiras como polvilho doce ou goma, é um pó fino branco, inodoro e insípido, que produz ligeira crepitação quando comprimido entre os dedos. Trata-se de polissacarídeo natural, da família química dos carboidratos constituídos de cadeias lineares (amilose) e cadeias ramificadas (amilopectina). Obtém-se a fécula à partir das raízes da mandioca, após descascamento, trituração, desintegração, purificação, peneiramento, centrifugação, concentração e secagem (CAMARGO et al., 1984).

De acordo com o IBGE (2010), a produção brasileira de mandioca em 2008 foi de 26,7 milhões de toneladas. $O$ estado do Pará se destaca como o maior produtor da raiz, com 4,8 milhões de toneladas por ano, seguido pela Bahia $(4,4)$, Paraná $(3,3)$, Maranhão $(1,7)$ e Rio Grande do Sul $(1,3)$. A quantidade de fécula de mandioca produzida no mesmo ano foi de 565 mil toneladas, sendo o Paraná o principal produtor (responsável por $62 \%$ da produção), seguido pelo Mato Grosso do Sul (19\%) e São Paulo (14\%) (ABAM, 2010).

O governo do estado do Pará, grande incentivador da cultura da mandioca, viabiliza ações por intermédio da Secretaria de Agricultura aos pequenos produtores. Os resultados do Programa PróMandioca têm mostrado que a cultura responde com alta produtividade, quando manejada com tecnologia (CARDOSO, 2004).

A utilização da fécula de mandioca em substituição de parte da farinha de trigo na fabricação de pão, macarrão e biscoito, tem sido tema de muitas pesquisas realizadas por órgãos oficiais e assunto de reportagens em revistas especializadas. Tramita na Câmara dos Deputados o Projeto de Lei 5332/09, da deputada Elcione Barbalho (PMDB-PA), que exige a adição de farinha, de raspa ou de fécula de mandioca ao trigo adquirido pelo Poder Público. A proporção adicionada à farinha de trigo deverá ser de $3 \%$ no primeiro ano de vigência da nova lei, elevada para $6 \%$ no segundo ano e para $10 \%$ no terceiro ano (BRASIL, 2010).

A fécula de mandioca é constituída, em média, por $18 \%$ de amilose e $82 \%$ de amilopectina. Nos amidos de cereais, a amilose ocorre em porcentagens que variam de $20 \%$ a $25 \%$ (CEREDA et al., 2001). As féculas gelatinizam em temperaturas inferiores, quando comparada ao amido (Tabela 1). Essa propriedade permite que se possa trabalhar com temperaturas mais baixas em algumas aplicações.

\section{TABELA 1 - TEMPERATURA DE GELATINIZAÇÃO DE SUSPENSÕES DE AMIDO E FÉCULA A 8\%}

\begin{tabular}{lc}
\hline \multicolumn{1}{c}{ Amido ou fécula } & Faixa de gelatinização $\left({ }^{\circ} \mathbf{C}\right)$ \\
\hline Amido de milho & $75-80$ \\
Fécula de batata & $60-65$ \\
Fécula de mandioca & $65-70$ \\
\hline
\end{tabular}

Fonte: ARIAS (2000).

Vários fatores devem ser considerados na utilização de farinhas mistas para produção de alimentos. As características das farinhas sucedâneas devem reduzir ao máximo os efeitos da substituição para se obter alimentos com cor aceitável, sabor agradável e boa textura (MARANGONI, 2007).

Pão é o produto obtido pela cocção, em condições tecnologicamente adequadas, de massa fermentada ou não, preparada com farinha de trigo e/ou outras farinhas que contenham naturalmente proteínas formadoras de glúten, ou adicionada das mesmas e água, podendo conter outros ingredientes (BRASIL, 2000). 
O objetivo deste trabalho foi estudar a influência da adição parcial de fécula de mandioca na qualidade sensorial e propriedades físicas do pão popularmente conhecido como pão tipo chá.

\section{MATERIAL E MÉTODOS}

\subsection{MATÉRIAS-PRIMAS}

Todos os ingredientes empregados na elaboração dos pães foram adquiridos no comércio de Belém (PA): farinha de trigo panificável, fécula de mandioca, açúcar (sacarose), sal, reforçador, emulsificante, fermento biológico, margarina e leite em pó.

\subsection{EQUIPAMENTOS}

Foram utilizados os seguintes equipamentos: forno elétrico marca LAYR, com controle de temperatura acoplado; amassadeira elétrica marca G. PANIZ, modelo AR 15; divisora de massa marca METVISA; modeladora marca BRAESI; câmara de fermentação e batedeira industrial marca BRAESI.

\subsection{FORMULAÇÃO E PRODUÇÃO DO PÃO TIPO CHÁ}

Prepararam-se farinhas mistas substituindo 5, 10 e 15\%, em peso, da farinha de trigo por fécula de mandioca. Também foi elaborada uma formulação sem substituição da farinha de trigo pela fécula. A formulação básica utilizada na elaboração do pão tipo chá foi definida após testes preliminares, com diferentes proporções dos ingredientes, partindo da formulação cedida por uma indústria de panificação local (Belém - PA). As formulações utilizadas são apresentadas na Tabela 2. Empregouse o método massa direta na produção dos pães, no qual todos os ingredientes são adicionados no início ou durante a etapa de mistura.

TABELA 2 - FORMULAÇÃO UTILIZADA PARA ELABORAÇÃO DO PÃO TIPO CHÁ

\begin{tabular}{lcccc}
\hline \multirow{2}{*}{ Ingredientes } & \multicolumn{4}{c}{ Pão tipo chá (\%) } \\
\cline { 2 - 5 } & $\mathbf{0 \%}$ & $\mathbf{5 \%}$ & $\mathbf{1 0 \%}$ & $\mathbf{1 5 \%}$ \\
\hline Farinha de trigo & 100 & 95 & 90 & 85 \\
Fécula & 0 & 5 & 10 & 15 \\
\hline Água & 50 & 54 & 56 & 57 \\
Fermento & 2 & 2 & 2 & 2 \\
Sal & 1,7 & 1,7 & 1,7 & 1,7 \\
Açúcar & 16 & 16 & 16 & 16 \\
Margarina & 3 & 3 & 3 & 3 \\
Leite em pó & 1 & 1 & 1 & 1 \\
Emulsificante & 0,2 & 0,2 & 0,2 & 0,2 \\
Reforçador & 0,2 & 0,2 & 0,2 & 0,2 \\
\hline
\end{tabular}

A farinha e os demais ingredientes, com exceção do sal, foram misturados por aproximadamente 3 minutos até completa homogeneização Em seguida, iniciou-se a adição gradativa de água a $5^{\circ} \mathrm{C}$ com o objetivo de controlar a elevação de temperatura da massa durante a etapa de desenvolvimento do glúten. No início da formação da massa ( $\approx$ minutos) interrompeu-se o batimento. Após a adição 
do sal, o amassamento foi conduzido até obtenção de massa coesa, homogênea e lisa, que se desprendia bem das paredes da amassadeira. Determinou-se o ponto final dessa etapa pela formação do glúten, ou teste do "ponto de véu", caracterizado pela elasticidade e extensibilidade da massa ao ser esticada com as mãos. Nesse momento, a massa foi boleada e permaneceu em descanso (coberta para não ressecar) por 5 minutos. Dividiu-se a massa em pedaços de aproximadamente $60 \mathrm{~g}$, os quais foram transferidos para a modeladora para adquirirem o formato desejado. Os pães foram colocados na câmara de crescimento, permanecendo por 4 horas (fermentação). Após a fermentação, os pães foram cozidos em forno elétrico com temperatura média de $80^{\circ} \mathrm{C}$ por, aproximadamente, 20 minutos.

\subsection{ANÁLISES}

\subsubsection{Análises físico-químicas e reológicas}

A farinha de trigo, a fécula de mandioca e o produto final foram submetidos às análises de: umidade (AACC, 2000); acidez titulável; proteínas pelo método de Kjeldahl; lipídios por extração com éter de petróleo (AOAC, 1997), cinzas das farinhas por incineração a $920^{\circ} \mathrm{C}$ (BRASIL, 1996); cinzas da fécula por incineração a $550^{\circ} \mathrm{C}$ (AOAC, 1997); cinzas do pão por incineração a $550^{\circ} \mathrm{C}$ (AACC, 2000); fibra alimentar total das farinhas e da fécula pelo método enzimático-gravimétrico (AOAC, 1997); glúten das farinhas em sistema Glutomatic (AACC, 2000); e volume específico, mediante deslocamento de sementes de painço, conforme metodologia proposta por ELÍAS e CONDÉ (1985).

A resistência das massas, com as diferentes proporções de farinha de trigo e fécula de mandioca, foi determinada em farinógrafo de acordo com o método 54-21 da AACC (2000). A força das farinhas (W) e razão $P / L$ foram determinadas em alveógrafo, conforme o método 54-30A da AACC (2000). Na determinação do Falling Number das farinhas utilizou-se o método 56-81B da AACC (2000), fundamentado na rápida gelatinização do amido em suspensão aquosa quando submetido ao aquecimento em banho-maria $\left(\approx 100^{\circ} \mathrm{C}\right)$ e na subsequente liquefação do gel formado pela ação da áamilase presente na amostra.

\subsubsection{Análises físicas}

Determinou-se a cor dos produtos por colorimetria tristimulus mediante leitura direta em colorímetro digital da marca KONICA MINOLTA, modelo CR-400. O colorímetro emite um feixe de luz sobre a amostra, o qual se decompõe em três partes distintas $\left(L^{*}, a^{*} e b^{*}\right)$, que se dirigem cada uma para um fotossensor acoplado em filtro ótico específico. O resultado expressa a variação de cor (Ä̈*), dada pela Equação 1 (CHROMA METER, 1989):

$$
\Delta \mathrm{E}^{*}=\left(\mathrm{a}^{* 2}+\mathrm{b}^{* 2}+\mathrm{L}^{* 2}\right)^{1 / 2}
$$

A atividade de água dos produtos foi determinada de acordo com o manual do equipamento, higrômetro AQUAlab 3TE da Decagon, mediante leitura direta, após equilíbrio da amostra com o ambiente à temperatura de $26,4^{\circ} \mathrm{C}$.

A perda de umidade e as transformações ocorridas durante o cozimento das farinhas mistas foram avaliadas por análise térmica gravimétrica (ATG) e análise térmica diferencial (ATD), em equipamento PL - STA da Thermal Sciences (DICKERSON, 1969).

A farinha de trigo, a fécula de mandioca e as farinhas mistas foram submetidas à caracterização morfológica, mediante microscopia eletrônica de varredura (MEV), em equipamento modelo LEO1430, com corrente do feixe de elétrons de $90 \mu \mathrm{A}$, voltagem de aceleração constante de $15 \mathrm{kv}$, distância de trabalho de $15 \mathrm{~mm}$ e elétrons secundários como tipo de imagens. 


\subsubsection{Avaliação microbiológica}

A avaliação microbiológica dos pães foi realizada de acordo com VANDERZANT e SPLITSTOESSER (1992). Coliformes a $45^{\circ} \mathrm{C}$ e Salmonella sp. foram determinados segundo padrões microbiológicos recomendados pela legislação brasileira (BRASIL, 2001).

\subsubsection{Análise sensorial}

Os produtos elaborados foram submetidos à análise sensorial, mediante testes de aceitação e intenção de compra. Os testes foram realizados com 30 julgadores não treinados, de ambos os sexos, sendo os produtos apresentados acompanhados apenas de água.

Os testes de aceitação foram realizados, com escala hedônica de nove pontos (STONE e SIDEL, 1993), avaliando-se os atributos: cor, aroma, sabor e maciez. As amostras foram codificadas com três dígitos e os julgadores selecionados aleatoriamente. $O$ teste de intenção de compra ocorreu após o teste de aceitabilidade pelos mesmos julgadores.

Para os cálculos do índice de aceitação (IA) e índice de intenção de compra (IC) utilizou-se a Equação 2, em que $M$ corresponde à média das notas obtidas e $X$ à nota máxima ( 9 para o teste de aceitabilidade e 5 para o teste de intenção de compra):

$$
I A \text { ou } I C=\frac{M}{X} \times 100 \%
$$

Os resultados dos testes sensoriais foram submetidos à análise estatística (Análise de Variância -ANOVA) para identificar a existência ou não de diferença significativa entre a aceitação dos produtos elaborados, de acordo com o teste de Tukey (DUTCOSKY, 1996).

\section{RESULTADOS E DISCUSSÃO}

\subsection{CARACTERIZAÇÃO FÍSICO-QUÍMICAE REOLÓGICADAS FARINHAS}

Na Tabela 3 são apresentados os valores médios, com os respectivos desvios-padrões, da composição e de parâmetros de qualidade das farinhas utilizadas. O teor de cinzas da farinha de trigo está de acordo com o recomendado pela Portaria $n^{\circ} 263$ (BRASIL, 2005), que permite no máximo $0,80 \%$ desse constituinte em base seca.

A fécula de mandioca mostrou valores de umidade de acordo com os padrões recomendados pela ANVISA (BRASIL, 2005), que permite no máximo 18\%. A acidez das farinhas apresentou-se de acordo com OCRIM DO PARÁ (2000) e as umidades da farinha de trigo e das farinhas mistas enquadramse nos limites estipulados pela legislação brasileira (BRASIL, 2005).

Os valores de glúten (glúten úmido e índice de glúten) demonstraram que as farinhas continham glúten de boa qualidade, com boa capacidade de absorção de água. Índices inferiores a 40 indicam glútens de baixa qualidade, entre 40-60 observam-se índices provenientes de farinhas médias, e os superiores a 60 estão relacionados com glútens de boa qualidade.

Em termos de panificação, o principal interesse está voltado para o teor de proteínas da farinha, responsável pela formação estrutural do pão, seu volume e rendimento (retenção de umidade). Partindo da etapa de mistura, as proteínas glutenina (responsável pela elasticidade) e gliadina (responsável pela extensibilidade) irão formar o glúten (TEDRUS et al., 2001). 
TABELA 3 - COMPOSIÇÃO MÉDIA E QUALIDADE TECNOLÓGICA DAS FARINHAS

\begin{tabular}{lccccc}
\hline \multicolumn{1}{c}{ Determinações } & $\begin{array}{c}\text { Farinha de } \\
\text { trigo }\end{array}$ & $\begin{array}{c}\text { Fécula de } \\
\text { mandioca }\end{array}$ & $\begin{array}{c}\text { Farinha } \\
\text { mista 5\% }\end{array}$ & $\begin{array}{c}\text { Farinha } \\
\text { mista 10\% }\end{array}$ & $\begin{array}{c}\text { Farinha } \\
\text { mista 15\% }\end{array}$ \\
\hline Glúten úmido** & $24,70 \pm 0,22$ & - & $25,53 \pm 0,43$ & $23,50 \pm 1,30$ & $24,38 \pm 0,21$ \\
Glúten seco** & $8,53 \pm 0,10$ & - & $8,73 \pm 0,17$ & $8,80 \pm 0,66$ & $8,50 \pm 0,11$ \\
Umidade (\%b.u.)* & $13,53 \pm 0,02$ & $13,99 \pm 0,04$ & $14,04 \pm 0,04$ & $13,40 \pm 0,24$ & $13,83 \pm 0,23$ \\
Cinzas (\%b.s.)* & $0,58 \pm 0,1$ & $0,11 \pm 0,3$ & $0,60 \pm 0,1$ & $0,52 \pm 0,1$ & $0,41 \pm 0,1$ \\
Acidez (mL sol. N de & $0,442 \pm 0,006$ & $0,149 \pm 0,01$ & $0,395 \pm 0,005$ & $0,372 \pm 0,006$ & $0,339 \pm 0,0$ \\
NaOH/100 g) & & & & & \\
Proteínas (\%b.s.)* & $10,13 \pm 1,0$ & $0,17 \pm 0,0$ & $10,11 \pm 0,01$ & $9,54 \pm 0,1$ & $9,06 \pm 0,01$ \\
Lipídios (\%b.u.)* & $1,01 \pm 0,3$ & $0,21 \pm 0,05$ & $1,11 \pm 0,1$ & $1,06 \pm 0,03$ & $1,01 \pm 0,05$ \\
Fibras Totais (\%b.u.)* & $3,2 \pm 0,11$ & $0,28 \pm 0,02$ & - & - & - \\
Índice de glúten** & $98 \pm 1$ & - & $98 \pm 0$ & $98 \pm 1$ & $98 \pm 1$ \\
Falling Number (s)** & $393 \pm 21$ & - & $393 \pm 5$ & $358 \pm 15$ & $456 \pm 19$ \\
\hline
\end{tabular}

* Média de três determinações; ** Média de quatro determinações; b.u. = base úmida; b.s. = base seca.

Os valores de Falling Number, na faixa de 300 a 400 seg, indicam que a ação da enzima áamilase foi baixa nas amostras analisadas. A farinha de trigo utilizada como base pode ter sido originada de trigo não germinado e estava em boas condições de armazenamento. A $\alpha$-amilase atua principalmente sobre o amido danificado e no amido gelatinizado, provocando a quebra das cadeias do amido e diminuindo a viscosidade da suspensão (MÓDENES, SILVA e TRIGUEROS 2009).

Com base no farinograma (Tabela 4) verificou-se que a substituição de 15\% da farinha de trigo contribuiu consideravelmente para a redução do tempo de desenvolvimento $(71,43 \%$ em relação à farinha de trigo) e do tempo de estabilidade ( $76 \%$ em relação à farinha de trigo). Esse nível de adição (15\%) proporcionou a perda da resistência da farinha de trigo durante as etapas de processamento (amassamento, divisão, boleamento, fermentação) do pão. A substituição de 15\% de farinha de trigo por fécula de mandioca mostrou-se inadequada para a produção de pão tipo chá, considerando as características físico-químicas e reológicas da farinha de trigo utilizada neste trabalho. As demais farinhas (5 e 10\% de substituição) não apresentaram efeito tão pronunciado quanto à de $15 \%$ nos aspectos de resistência da rede de glúten formada e podem ser utilizadas para a produção de pão tipo chá sem danos à sua qualidade física.

TABELA 4 - FARINOGRAMA DAS FARINHAS DE TRIGO E MISTAS

\begin{tabular}{lcccc}
\hline \multicolumn{1}{c}{ Determinaçöes } & Farinha de trigo & $\begin{array}{c}\text { Farinha mista } \\
\mathbf{5 \%}\end{array}$ & $\begin{array}{c}\text { Farinha mista } \\
\mathbf{1 0} \%\end{array}$ & $\begin{array}{c}\text { Farinha mista } \\
\mathbf{1 5 \%}\end{array}$ \\
\hline Abs. (\%) & 56,5 & 56,0 & 56,6 & 58,2 \\
T.Ch. (min) & 1,0 & 1,0 & 1,0 & 1,0 \\
T. Des. (min) & 7,0 & 10,0 & 7,0 & 2,0 \\
T. Est. (min) & 12,5 & 13,5 & 12,0 & 3,0 \\
\hline
\end{tabular}

Abs. = absorção de água; T.Ch. = Tempo de chegada; T.Des. = Tempo de desenvolvimento; T.Est. = Tempo de estabilidade. 
A análise alveográfica (Tabela 5) revelou que todas as farinhas apresentaram características mais elásticas, ou seja, maior tenacidade que extensibilidade. Tal constatação pode ser confirmada pelos valores da relação P/L (índice de configuração da curva ou relação entre a pressão máxima e a abscissa média de ruptura) e de W (energia de deformação da massa ou força da farinha).

TABELA 5 - ALVEOGRAMA DAS FARINHAS DE TRIGO E MISTAS

\begin{tabular}{|c|c|c|c|c|}
\hline Determinaçöes & Farinha de trigo & $\begin{array}{c}\text { Farinha mista } \\
5 \%\end{array}$ & $\begin{array}{c}\text { Farinha mis ta } \\
10 \%\end{array}$ & $\begin{array}{c}\text { Farinha mista } \\
15 \%\end{array}$ \\
\hline$\overline{P(\mathrm{~mm})}$ & 83 & 112 & 87 & 104 \\
\hline$L(m m)$ & 68 & 46 & 68 & 58 \\
\hline$P /$ & 1,22 & 2,43 & 1,34 & 1,79 \\
\hline$W\left(\times 10^{-4} \mathrm{~J}\right)$ & 220 & 220 & 220 & 250 \\
\hline
\end{tabular}

$\mathrm{P}=$ Pressão máxima; $\mathrm{L}=$ Abscissa média; $\mathrm{P} / \mathrm{L}=$ Índice de configuração da curva; $\mathrm{W}=$ Energia de deformação da massa.

\subsection{ANÁLISE MORFOLÓGICADAS FARINHAS}

Na Figura 1 podem ser visualizadas as micrografias da fécula de mandioca e da farinha de trigo e na Figura 2 as das três farinhas mistas. Os grânulos de amido presentes na fécula de mandioca (Figura 1A) constituem massa homogênea com forma, predominantemente, oval ou esférica, sendo alguns côncavo-convexos característicos. Já os grânulos de amido da farinha de trigo (Figura 1B) apresentam formato esférico ou lenticular.

Pôde-se estimar, a partir das micrografias, que o diâmetro dos grânulos de amido da mandioca (fécula de mandioca) variou de 4 a $15 \mu \mathrm{m}$, com média de $10 \mu \mathrm{m}$. Já o diâmetro dos grânulos de amido do trigo variou de 10,5 a $28 \mu \mathrm{m}$, com média de $19 \mu \mathrm{m}$. A Figura 2 evidencia que quando maior a quantidade de fécula, maior é a predominância das formas mais regulares do amido constituinte da fécula de mandioca.

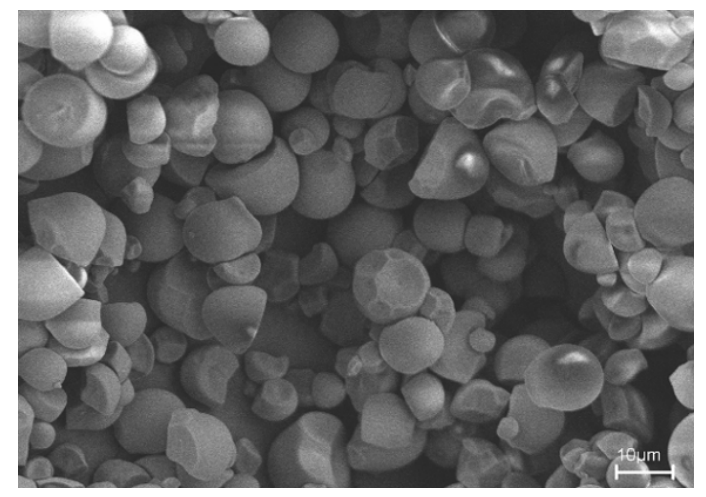

(A)

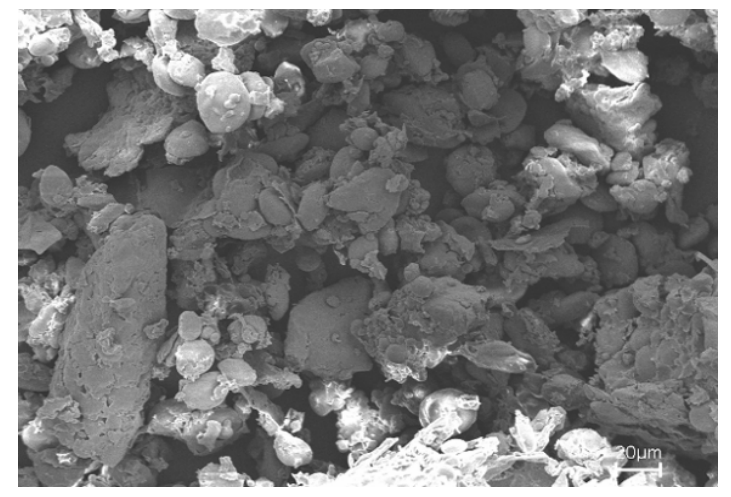

(B)

FIGURA 1 - MICROSCOPIA ELETRÔNICA DE VARREDURA (MEV): (A) FÉCULA DE MANDIOCA E (B) FARINHA DE TRIGO 


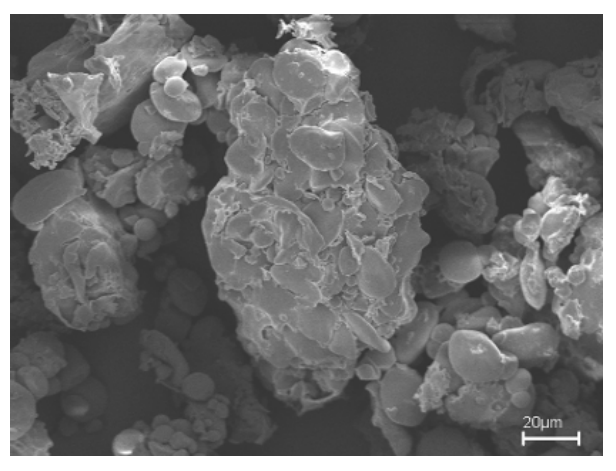

(A)

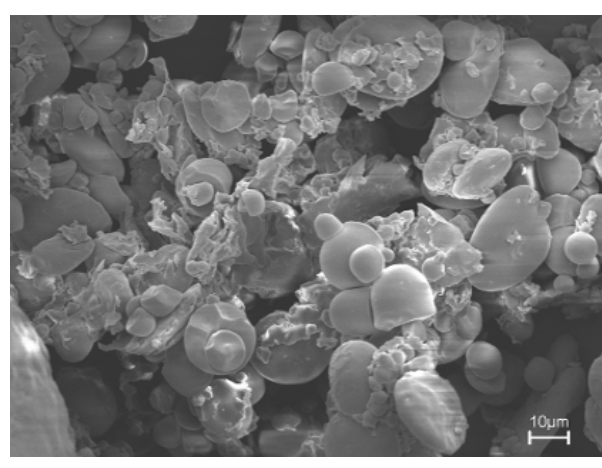

(B)

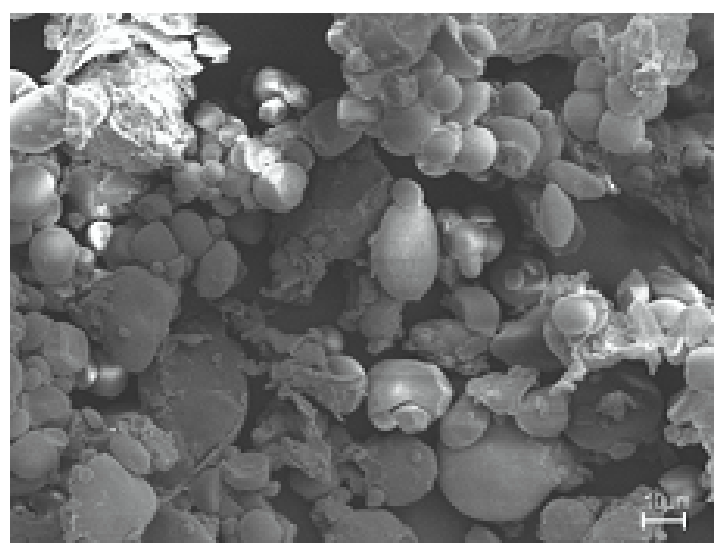

(C)

\section{FIGURA 2 - MICROSCOPIA ELETRÔNICA DE VARREDURA (MEV) DAS FARINHAS MISTAS: (A) $5 \%,(B) 10 \%$ E (C) 15\% DE FÉCULA DE MANDIOCA}

\subsection{ANÁLISE TÉRMICA DAS FARINHAS}

Os resultados da análise térmica diferencial (ATD), aplicada à farinha de trigo, fécula de mandioca e farinhas mistas, foram avaliados até a temperatura de $200^{\circ} \mathrm{C}$ (temperatura máxima de forneamento no processamento do pão tipo chá). AATD de todas as farinhas apresentou um único pico (endotérmico), a aproximadamente $65^{\circ} \mathrm{C}$, característico da gelatinização do amido. Não foi observado deslocamento significativo desse pico $(p \leq 0,05)$, conforme aumento do percentual de fécula de mandioca na farinha mista, nem em relação à farinha de trigo utilizada.

\subsection{CARACTERIZAÇÃO FÍSICO-QUÍMICA DO PÃO TIPO CHÁ}

Os resultados das análises físicas e físico-químicas efetuadas no pão tipo chá são apresentados nas Tabelas 6 e 7, respectivamente. As análises físico-químicas foram realizadas apenas para a formulação padrão e para a formulação que apresentou os melhores resultados.

As diferentes formulações de pão tipo chá apresentaram volumes específicos abaixo do mínimo sugerido por PIZZINATTO, LEITÃO e VITTI (1990). Pode-se observar que quanto maior o teor de fécula adicionado, menor foi o volume específico do pão, indicando que o aumento na quantidade de fécula adicionada interfere negativamente sobre essa variável. 
O peso dos pães atendeu o mínimo de $50 \mathrm{~g}$, estabelecido pela portaria №03/97 do INMETRO (BRASIL, 1997), e a umidade o limite de 38\% fixado pela ANVISA (BRASIL, 2000). Já os valores de atividade de água $\left(a_{w}\right)$ não conferem estabilidade microbiológica aos produtos, que é obtida em $a_{w}<0,6$.

TABELA 6 - CARACTERÍSTICAS FÍSICAS DO PÃO TIPO CHÁ

\begin{tabular}{lcccc}
\hline \multirow{2}{*}{ Determinaçöes } & \multicolumn{4}{c}{ Formulação } \\
\cline { 2 - 5 } & $\begin{array}{c}\text { Padrăo } \\
(\mathbf{0} \% \text { de FM) }\end{array}$ & $\mathbf{5 \%}$ de FM & $\mathbf{1 0} \% \mathbf{F M}$ & $\mathbf{1 5 \%}$ FM \\
\hline Peso do pẫo cru $(\mathrm{g})$ & 53,33 & 58,3 & 63,3 & 61,6 \\
Temperatura da massa $\left({ }^{\circ} \mathrm{C}\right)$ & 24 & 25 & 23 & 24 \\
Peso do pẫo assado $(\mathrm{g})$ & $51,66 \pm 0,28$ & $56,6 \pm 0,28$ & $58,30 \pm 0,28$ & $53,3 \pm 0,30$ \\
Volume específico $\left(\mathrm{cm}^{3} / \mathrm{g}\right)$ & $4,59 \pm 0,40$ & $3,95 \pm 0,34$ & $3,80 \pm 0,23$ & $3,57 \pm 0,38$ \\
\hline
\end{tabular}

* Média de três determinações; FM = fécula de mandioca.

TABELA 7 - CARACTERÍSTICAS FÍSICO-QUÍMICAS DO PÃO TIPO CHÁ

\begin{tabular}{lcc}
\hline \multirow{2}{*}{ Determinaçöes* $^{*}$} & \multicolumn{2}{c}{ Formulaçäo } \\
\cline { 2 - 3 } & Padräo (0\% de FM) & $\mathbf{1 0} \% \mathbf{d e ~ F M ~}$ \\
\hline Umidade (\%b.u.) & $29,78 \pm 0,71$ & $32,12 \pm 0,25$ \\
Cinzas (\%b.s.) & $1,02 \pm 0,08$ & $0,95 \pm 0,13$ \\
Proteínas (\%b.u.) & $5,88 \pm 0,23$ & $4,71 \pm 0,30$ \\
Lipídios (\%b.u.) & $3,47 \pm 0,12$ & $3,48 \pm 0,11$ \\
Atividade de água do miolo & $0,86 \pm 0,050$ & $0,89 \pm 0,008$ \\
Cor do miolo ( $\Delta \mathrm{E}^{*}$ ) & - & $2,23 \pm 0,29$ \\
\hline
\end{tabular}

* Média de três determinações; FM = fécula de mandioca; b.u. = base úmida; b.s. = base seca.

Constatou-se que a adição de fécula na formulação interferiu na coloração final do produto pelo valor de $\mathrm{ÄE}^{\star}(2,23)$ para o pão tipo chá com $10 \%$ de fécula de mandioca, o qual representa a variação de cor em relação ao pão sem fécula.

\subsection{ANÁLISE MICROBIOLÓGICA}

As análises microbiológicas realizadas nas formulações de pão tipo chá com 0, 5, 10 e 15\% de fécula de mandioca, não detectaram ocorrências de coliformes a $45^{\circ}$ e Salmonella sp. em níveis acima dos padrões estabelecidos pela legislação brasileira (BRASIL, 2001).

\subsection{ANÁLISE SENSORIAL}

Os índices de aceitação (IC) obtidos para as diferentes formulações de pão tipo chá são apresentados na Tabela 8. A ANOVA dos resultados do teste de aceitação aplicado às diferentes formulações de pão tipo chá demonstrou que os atributos cor, aroma e sabor não apresentaram 
diferença significativa entre as formulações $(p \geq 0,05)$. A maciez foi o único atributo avaliado que apresentou diferença significativa $(p \leq 0,05)$, mostrando tendência de redução na aceitação desse parâmetro pelo incremento de fécula de mandioca na formulação de pão tipo chá.

O resultado do teste de intenção de compra aplicado às diferentes formulações indicou que os pães tipo chá elaborados sem a adição de fécula e aqueles com as farinha mista a 5 e 10\% alcançaram na somatória da nota dos quesitos "certamente compraria" e "provavelmente compraria", respectivamente, 97\%, 96\% e 97\%. Já a formulação com 15\% apresentou somatória de $69 \%$ para os mesmos quesitos. Isso demonstra que qualquer substituição da farinha de trigo por fécula de mandioca deve ser previamente avaliada, pois há o risco de perda da qualidade final do produto.

\section{TABELA 8 - ÍNDICE DE ACEITAÇÃO PARA AS DIFERENTES FORMULAÇÕES DE PÃO TIPO CHÁ}

\begin{tabular}{lcccc}
\hline Formulação & Cor $^{*}$ & Aroma $^{*}$ & Sabor* $^{*}$ & Maciez $^{*}$ \\
\hline Branco & $84,44^{\mathrm{a}}$ & $90,00^{\mathrm{a}}$ & $87,78^{\mathrm{a}}$ & $92,22^{\mathrm{a}}$ \\
A (5\%) & $83,33^{\mathrm{a}}$ & $88,15^{\mathrm{a}}$ & $85,56^{\mathrm{a}}$ & $88,89^{\mathrm{b}}$ \\
B (10\%) & $88,15^{\mathrm{a}}$ & $86,30^{\mathrm{a}}$ & $91,11^{\mathrm{a}}$ & $86,67^{\mathrm{b}}$ \\
C (15\%) & $84,44^{\mathrm{a}}$ & $90,00^{\mathrm{a}}$ & $88,15^{\mathrm{a}}$ & $84,07^{\mathrm{b}}$
\end{tabular}

* Letras diferentes nas colunas indicam diferença significativa $(p \leq 0,05)$.

Com base nas características reológicas (tempo de desenvolvimento e tempo de estabilidade), volume específico, teor de glúten e intenção de compra comprovou-se a viabilidade de substituição da farinha de trigo por fécula de mandioca no máximo em 10\%, considerando as características reológicas próprias da farinha de trigo empregada neste trabalho.

\section{CONCLUSÃO}

De acordo com os níveis de substituição estudados (5, 10 e 15\%), os resultados obtidos mostraram que é possível substituir em até $10 \%$ a farinha de trigo pela fécula de mandioca para a produção de pão tipo chá, considerando a farinha de trigo empregada no trabalho. A substituição de $15 \%$ proporcionou danos à qualidade física e sensorial dos pães produzidos.

\section{ABSTRACT \\ ADDITION OF CASSAVA FLOUR IN THE FORMULATION OF THE TEA BREAD}

In this work was studied the partial substitution of wheat flour by cassava flour in tea bread formulation. Physico-chemical analyses, differential thermal analyses (DTA) and scanning electron microscopy (SEM) were used to characterize the wheat, the cassava and mixed flours (with 5, 10 and 15\% substitution of wheat flour by cassava flour). The substitution with cassava flour until $10 \%$ did not change significantly $(p \leq 0.05)$ the sensory quality and physical properties of the tea bread.

KEY-WORDS: CASSAVA FLOUR; WHEAT FLOUR; TEA BREAD.

\section{REFERÊNCIAS}

1 AACC. American Association of Cereal Chemists. Approved methods of the AACC. $10^{\text {th }}$ ed. St. Paul, 2000.

2 ABAM. Associação Brasileira dos Produtores de Amido de Mandioca. Produção brasileira de amido por estado 2008. Disponível em: <http://www.abam.com.br>. Acesso em: 12 fev. 2010. 
3 AOAC. Association of Official Analytical Chemists. Official methods of analysis of the AOAC International. $16^{\text {th }}$ ed. $3^{\text {rd }}$ rev. Washington, 1997.

4 ARIAS, L.V.B. Fécula de mandioca e polvilho azedo para fabricação de pão de queijo. In: PIZZINATTO, A.; ORMESE, R.C.S.S. Seminário pão de queijo: ingredientes, formulação e processo. Campinas: Governo do estado de São Paulo/Secretaria de Agricultura e Abastecimento/Agência Paulista de Tecnologia dos Agronegócios/Instituto de Tecnologia de Alimentos/ Centro de Tecnologia de Cereais e Chocolate, 2000. p.1-14.

5 BRASIL. Agência Nacional de Vigilância Sanitária. Portaria $n^{\circ}$ 354, de 18 de julho de 1996. Aprova a norma técnica referente a farinha de trigo. Diário Oficial [da] República Federativa do Brasil, Brasília, 22 jul. 1996. Secção 1, p.57.

6 BRASIL. Agência Nacional de Vigilância Sanitária. Resolução RDC nº 263, de 22 de setembro de 2005. Regulamento técnico para produtos de cereais, amidos, farinhas e farelos. Diário Oficial [da] República Federativa do Brasil, Brasília, 23 set. 2005. Seç̧ão 1, p.368.

7 BRASIL. Agência Nacional de Vigilância Sanitária. Resolução RDC n 90, de 18 de outubro de 2000. Regulamento técnico para fixação de identidade e qualidade de pão. Diário Oficial [da] República Federativa do Brasil, Brasília, 20 out. 2000. Secção 1, p.29.

8 BRASIL. Agência Nacional de Vigilância Sanitária. Resolução RDC n 12, de 02 de janeiro de 2001. Regulamento técnico sobre padrões microbiológicos para alimentos. Diário Oficial [da] República Federativa do Brasil], Brasília, 10 jan. 2001. Secção 1, p.45.

9 BRASIL. Câmara dos Deputados. Projeto exige adição de mandioca à farinha de trigo. Disponível em: <http:// www2.camara.gov.br/agencia/noticias/ 139239.html>. Acesso em: 12 fev. 2010.

10 BRASIL. Instituto Nacional de Metrologia, Normalização e Qualidade Industrial. Portaria no 3, de 10 de janeiro de 1997. Dispõe sobre a comercialização do pão francês, ou de sal, a peso (pesagem na presença do consumidor) ou unidades de peso nominal definido. Diário Oficial [da] República Federativa do Brasil, Brasília, 15 jan. 1997. Seção 1, p.816.

11 BRASIL. Ministério da Agricultura, Pecuária e Abastecimento. Instrução Normativa nº 8, de 2 de junho de 2005. Regulamento técnico de identidade e qualidade da farinha de trigo. Diário Oficial [da] República Federativa do Brasil, Brasília, 03 jun. 2005. Secção 1, p.91.

12 CAMARGO, R.; FONSECA, H.; CARASO, J.G.B.; GRANER, M.; ANDRADE, M.A.; NOGERA, J.N.; CANTARELA, P.R. Tecnologia de produtos agropecuários: alimentos. São Paulo: Nobel, 1984. $289 \mathrm{p}$.

13 CARDOSO, C.E.L. Competitividade e inovação tecnológica na cadeia agroindustrial de fécula de mandioca no Brasil. 2004. 188 f. Tese (Doutorado em Economia Aplicada), Universidade de São Paulo, Piracicaba, 2004.

14 CEREDA, M.P.; CHUZEL, G.C.; VILPOUX, O.; NUNES, O.L.G.S. Biotecnologia industrial. In: MODIFICAÇÃO de fécula por fermentação. São Paulo: Edgard Blücher, 2001. p. 413-460.

15 CHROMA METER CT-310. Instruction manual. Osaka (Japan): Minolta Carnera Co. LTD., 1989. 87 p.

16 DICKERSON, R.W. Thermal properties of foods in the freezing preservation of foods. $4^{\text {th }}$ ed. Westport: AVI Publishing, 1968. p.26-51.

17 DUTCOSKY, S.D. Análise sensorial de alimentos. Curitiba: Champagnat, 1996. 123 p.

18 ELÍAS, J.R.; CONDÉ, A.P. El processo de panificacion: etapas fundamentales y papel de la farina em la mismas. Alimentaria, v.22, n.1, p.17-32, 1985

19 IBGE (Rio de Janeiro, RJ). Produção agrícola municipal 2008. Disponível em: <http://www.ibge.gov.br/ servidor_arquivos_est/>. Acesso em: 12 fev. 2010.

20 MARANGONI, A.L. Potencialidade de aplicação de farinha de Yacon (Polymnia sonchifolia) em produtos à base de cereais. 2007. 104 f. Dissertação (Mestrado em Ciência e Tecnologia de Alimentos), Universidade Estadual de Campinas, Campinas, 2007.

21 MÓDENES, A.N.; SILVA, A.M.; TRIGUEROS, D.E.G. Avaliação das propriedades reológicas do trigo armazenado. Ciência e Tecnologia de Alimentos, Campinas, v.29, n.3, p.508-512, 2009. 
23 PIZZINATTO, A.; LEITÃO, R.F.F.; VITTI, P. Curso de panificação. São Paulo: Secretaria de Agricultura e Abastecimento/ Instituto de Tecnologia de Alimentos, 1990. 50 p.

24 STONE, H.S.; SIDEL, J.L. Sensory evaluation practices. $2^{\text {nd }}$ ed. San Diego: Academic, 1993. 338 p.

25 TEDRUS, G.A.S.; ORMENESE, R.C.S.C.; SPERANZA, S.M.; CHANG, Y.K.; BUSTOS, F.M. Estudo da adição de vital glúten à farinha de arroz, farinha de aveia e amido de trigo na qualidade de pães. Ciência e Tecnologia de Alimentos, Campinas, v.21, n.1, p.20-25, 2001.

26 VANDERZANT, C., SPLITTSTOESSER, D.F. Compendium of methods for microbiological examination of foods. $3^{\text {rd }}$ ed. Washington, DC: American Public Health Association, 1992. 1108 p. 